\title{
Misdiagnosis of ameloblastoma in a patient with clear cell odontogenic carcinoma: a case report
}

\author{
Jong-Cheol Park', Seong-Won Kim¹, Young-Jae Baek', Hyeong-Geun Lee ${ }^{1}$, \\ Mi-Heon Ryu'², Dae-Seok Hwang', Uk-Kyu Kim ${ }^{1}$ \\ ${ }^{I}$ Department of Oral and Maxillofacial Surgery, School of Dentistry, Pusan National University, \\ ${ }^{2}$ Department of Oral Pathology, BK21 Plus Project, School of Dentistry, Pusan National University, Yangsan, Korea
}

\begin{abstract}
J Korean Assoc Oral Maxillofac Surg 2019;45:116-120)
Clear cell odontogenic carcinoma (CCOC), a rare tumor in the head and neck region, displays comparable properties with other tumors clinically and pathologically. In consequence, an incorrect diagnosis may be established. A 51-year-old male patient who was admitted to the Department of Oral and Maxillofacial Surgery at Pusan National University Dental Hospital was initially diagnosed with ameloblastoma via incisional biopsy. However, the excised mass of the patient was observed to manifest histopathological characteristics of ameloblastic carcinoma. The lesion was ultimately diagnosed as clear cell odontogenic carcinoma by the Department of Oral Pathology of Pusan National Dental University. Therefore, segmental mandibulectomy and bilateral neck dissection were performed, followed by reconstruction with fibula free flap and reconstruction plate. Concomitant chemotherapy radiotherapy was not necessary. The patient has been followed up, and no recurrence has occurred 6 months after surgery.
\end{abstract}

Key words: Neoplasms, Ameloblastoma, Clear cell odontogenic carcinoma

[paper submitted 2017. 9. 7 / revised 2017. 11. 13, / accepted 2017. 11. 22]

\section{Introduction}

Clear cell odontogenic carcinoma $(\mathrm{CCOC})$ is a rare tumor of the head and neck region, first described by Hansen et al. ${ }^{1}$ in 1985 and classified as a malignant carcinoma by the World Health Organization in $2005^{2}$. Due to its infrequency, diagnostic criteria, protocols, and prognosis of CCOC are not often not fully understood. Additionally, CCOC shares comparable clinical and pathological characteristics with other diseases, possibly leading to misdiagnoses. The authors report a case of CCOC mistaken for an ameloblastoma and discuss the factors that led to misdiagnosis as well as the characteristics of CCOC.

\footnotetext{
Uk-Kyu Kim

Department of Oral and Maxillofacial Surgery, Pusan National University Dental Hospital, 20 Geumo-ro, Mulgeum-eup, Yangsan 50612, Korea TEL: +82-55-360-5100 FAX: +82-55-360-5104

E-mail:kuksjs@pusan.ac.kr

ORCID: https://orcid.org/0000-0003-1251-7843

(c) This is an open-access article distributed under the terms of the Creative Commons Attribution Non-Commercial License (http://creativecommons.org/ licenses/by-nc/4.0/), which permits unrestricted non-commercial use, distribution, and reproduction in any medium, provided the original work is properly cited. Copyright (C) 2019 The Korean Association of Oral and Maxillofacial Surgeons. All rights reserved.
}

\section{Case Report}

A 51-year-old male patient was admitted to the Department of Oral and Maxillofacial Surgery at Pusan National University Dental Hospital (Yangsan, Korea) for pain and discomfort in the mandibular anterior region. The patient did not manifest any underlying disorders or noticeable lab results except controlled hypertension.

Under routine clinical examination, the patient reported pain and light mobility in four mandibular anterior teeth. Panoramic radiography and cone-beam computed tomography (CT) revealed an irregular $38 \times 31 \mathrm{~mm}$ lesion of the mandibular anterior region.(Fig. 1) Because radiologic findings did not provide conclusive evidence for diagnosis, incisional biopsy was conducted under local anesthesia. Based on histopathologic examination conducted at the Department of Pathology of Pusan National University Yangsan Hospital, the lesion was diagnosed as ameloblastoma.(Fig. 2)

Given the aggressive behavior of ameloblastoma, excision and mandibular reconstruction with iliac-block bone were performed under general anesthesia.(Fig. 3) The main mass from surgery was determined by Department of Pathology staff to be poorly differentiated ameloblastic carcinoma. 
However, the clinical features of the main mass did not correspond to those of a poorly differentiated ameloblastic carcinoma. The authors requested a histopathologic examination by the Department of Oral Pathology at Pusan National Dental University for more accurate analysis. Given the presence of multiple clear cells and clinical features, CCOC was the final diagnosis.(Fig. 4) After a one-month-long healing period, CT, magnetic resonance imaging, and positron emission tomography-CT scans were performed.(Fig. 5) A segmental mandibulectomy in the anterior region was performed along with bilateral neck dissection, followed by reconstruction with a right fibular free flap. Supraomohyoid neck dissection included levels I to III on the right and levels I and II on the left. Frozen biopsy on the margins of the lesion presented normal tissue findings. Permanent biopsy results produced
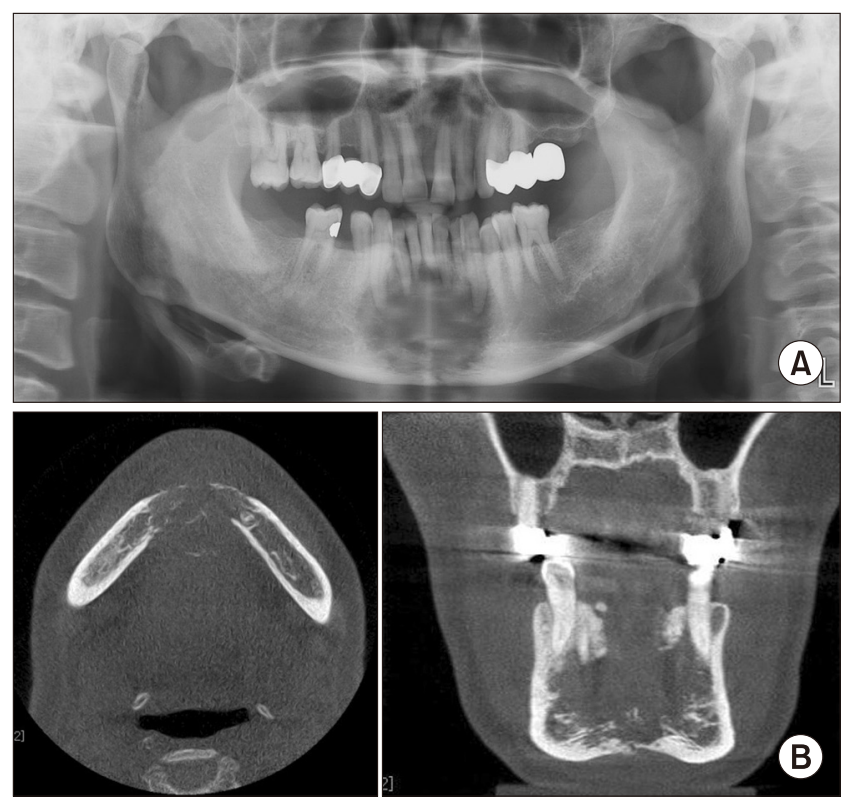

Fig. 1. Preoperative radiographs of panorama (A) and cone-beam computed tomography (B). Irregularly margined round lesion of 30 $\mathrm{mm}$ in diameter is observed in the middle of mandible.

Jong-Cheol Park et al: Misdiagnosis of ameloblastoma in a patient with clear cell odontogenic carcinoma: a case report. J Korean Assoc Oral Maxillofac Surg 2019 negative findings from the margins and suspected neck areas for possible metastasis, with the exception of the resection area. The surgical site exhibited positive recovery, requiring neither adjuvant chemotherapy nor radiotherapy. Continuous follow-up for seven months after surgery found no evidence of recurrence.(Fig. 6)

\section{Discussion}

CCOC is a rare odontogenic tumor that shows distinctive vacuolated clear cells. According to previous studies, it is most frequently seen in female patients, especially those in middle age ${ }^{3}$. Various clinical symptoms have been reported, including pain, distressing jaw enlargement, cortical bone damage, paresthesia, tooth mobility, and root resorption ${ }^{4}$. According to a recent, systematic review of CCOC patients,
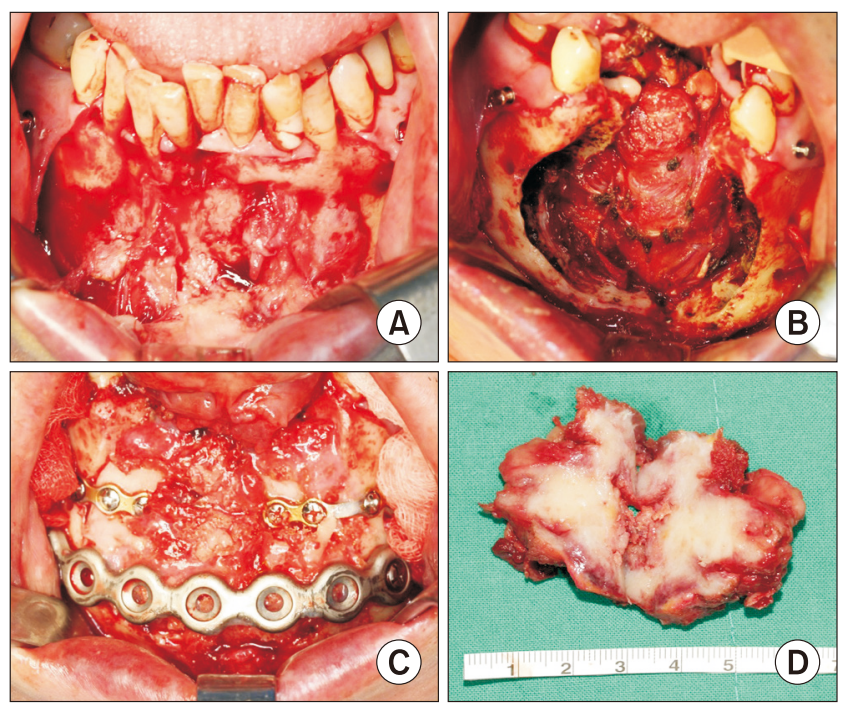

Fig. 3. Surgical procedure of 1st operation. A. Before excision. B. After excision. C. Mandibular reconstruction with lliac block bone and reconstruct plate. D. Excised mass.

Jong-Cheol Park et al: Misdiagnosis of ameloblastoma in a patient with clear cell odontogenic carcinoma: a case report. J Korean Assoc Oral Maxillofac Surg 2019
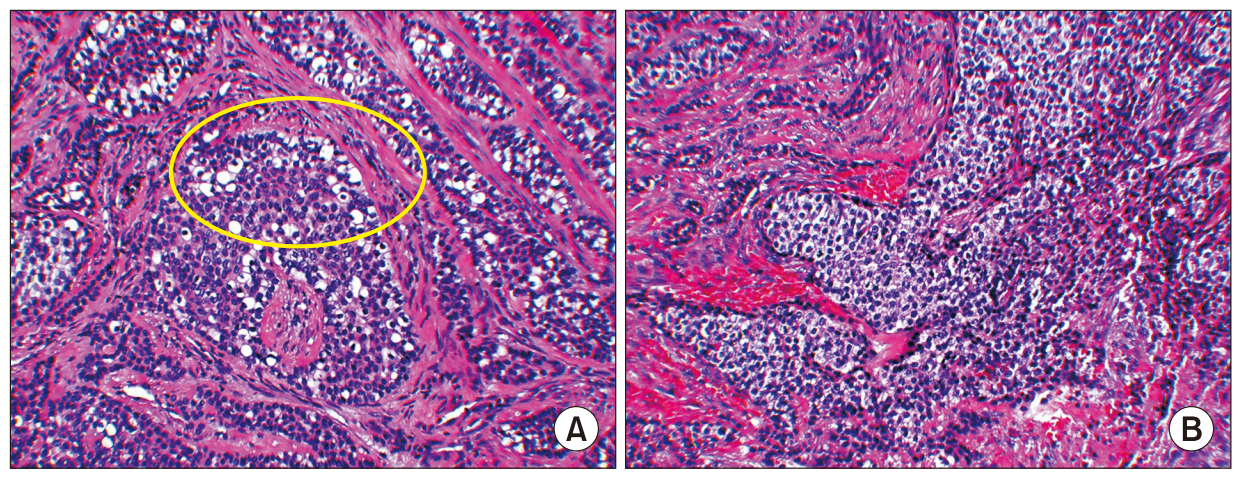

Fig. 2. Histopathologic findings of incisional biopsy (H\&E staining, $\times 200)$. A. Ameloblastic basal lamina structure was observed while several clear cells existed (circle). B. Hyperchromatic islands of basaloid epithelial cell were demonstrated.

Jong-Cheol Park et al: Misdiagnosis of ameloblastoma in a patient with clear cell odontogenic carcinoma: a case report. J Korean Assoc Oral Maxillofac Surg 2019 

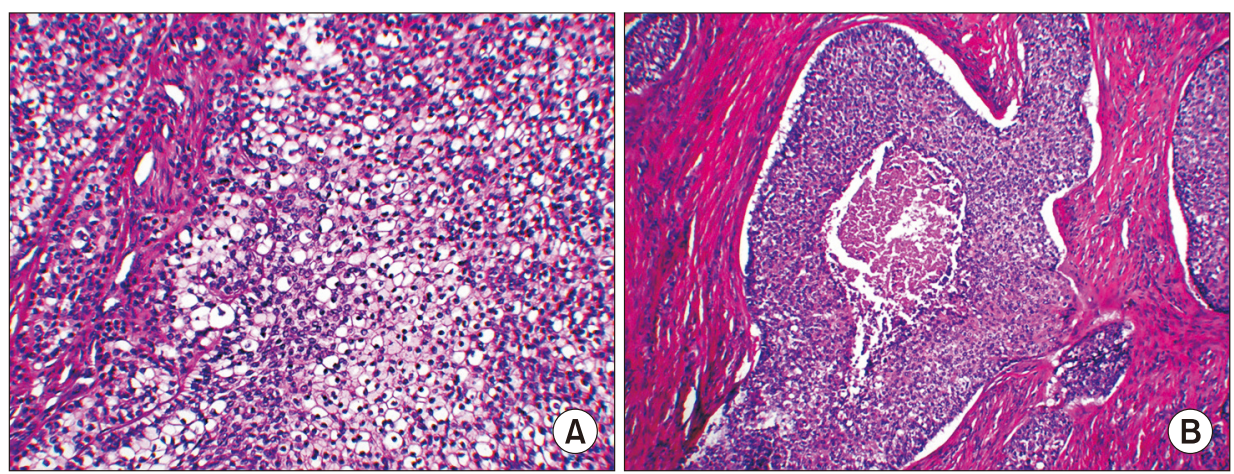

Fig. 4. Histopathologic findings of main mass. A. Diphasic differentiation of cells and cell island pattern were observed. Multiple clear cells showed nuclear hyperchromatism as well as dynamic mitosis, allowing diagnosis of malignancy (H\&E staining, ×200). B. Typical histological finding of malignant tumor (H\&E staining, $\times 100)$.

Jong-Cheol Park et al: Misdiagnosis of ameloblastoma in a patient with clear cell odontogenic carcinoma: a case report.J Korean Assoc Oral Maxillofac Surg 2019
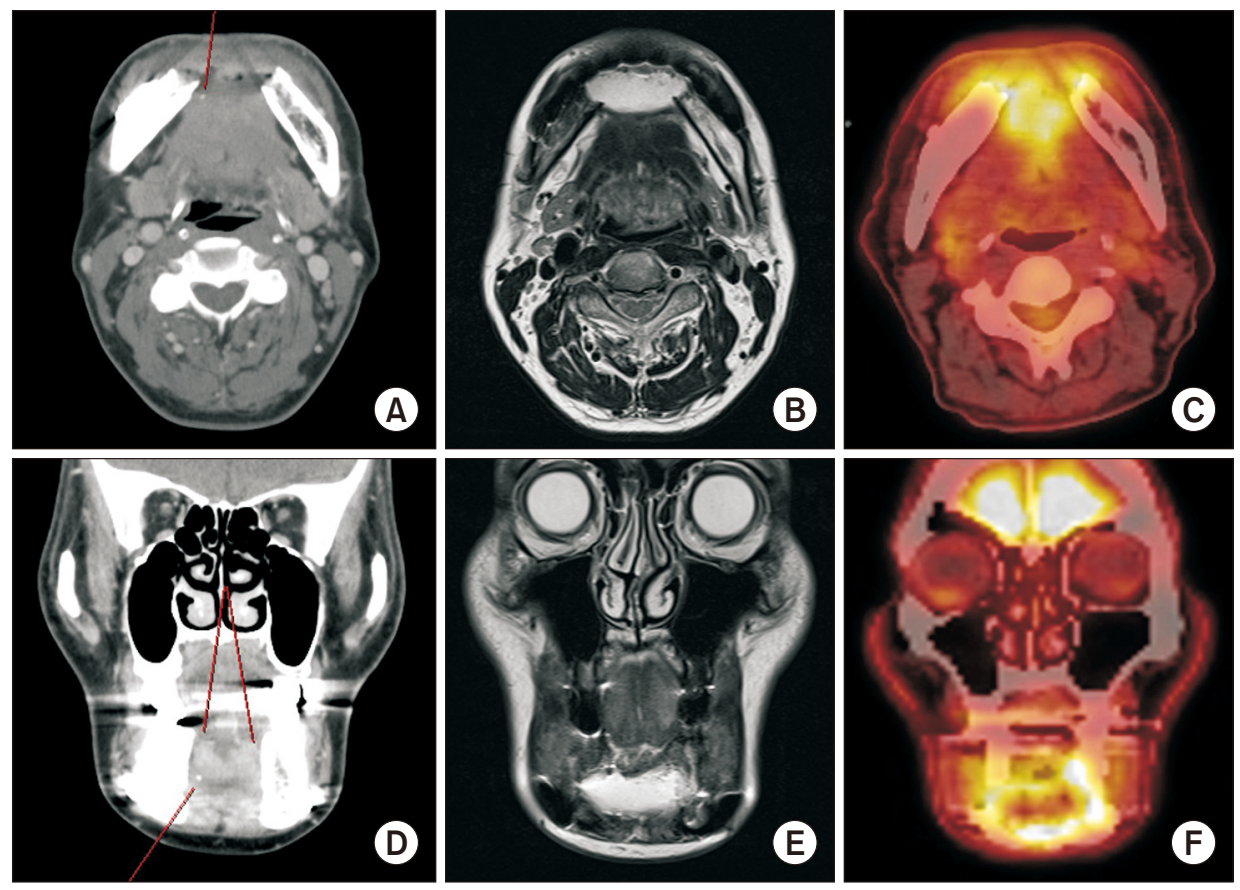

Fig. 5. There are radiographs after 1 st operation. A, D. Contrast-enhanced computed tomography (CT). B, E. Magnetic resonance imaging (T2-weighted images). C, F. Positron emission tomography-CT. Tumor cells invaded adjacent soft tissues even after removal of the lesion by the first operation.

Jong-Cheol Park et al: Misdiagnosis of ameloblastoma in a patient with clear cell odontogenic carcinoma: $a$ case report. J Korean Assoc Oral Maxillofac Surg 2019

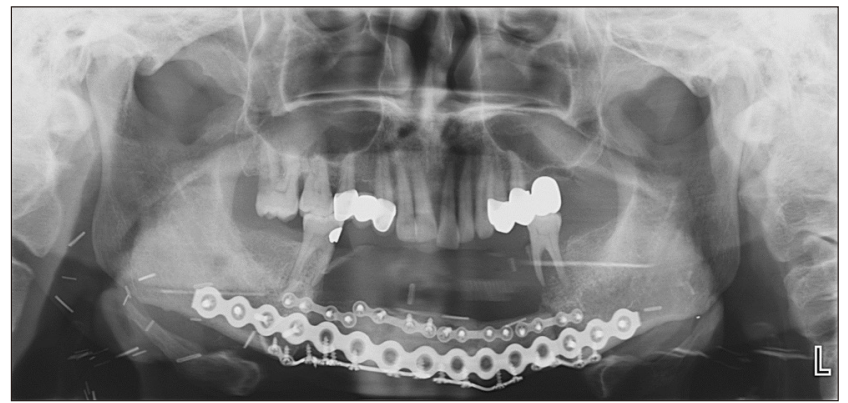

Fig. 6. Panoramic radiograph 7 months after surgery. No recurrence observed while reconstructed in favorable state.

Jong-Cheol Park et al: Misdiagnosis of ameloblastoma in a patient with clear cell odontogenic carcinoma: a case report. J Korean Assoc Oral Maxillofac Surg 2019

recurrence and metastasis are often observed ${ }^{5}$. Approximately $41 \%$ of patients experienced a local recurrence, $19 \%$ showed a regional metastasis to a level I lymph node, and $11.9 \%$ presented a distant metastasis, mostly to a lung. The morality rate was $14.3 \%$, while survival rates at 5,10 , and 20 years were $87 \%, 76 \%$, and $46 \%$, respectively. Although the first report on CCOC was published more than 30 years ago, disease etiology and predictive factors of cell differentiation remain poorly understood.

Differentiating CCOC from other diseases on a histological basis may be challenging. The histological patterns of CCOC include biphasic, monophasic, and ameloblastomatous variants $^{6}$. The biphasic pattern, the most common variant, is associated with nests of clear cells integrated with islands of eosinophilic, polygonal epithelial cells. The monophasic pattern contains nests and cords of clear cells only. The am- 
eloblastomatous pattern, the least common variant, resembles ameloblastomas that occasionally include palisading, peripheral clear cells ${ }^{7-10}$.

Recently, a DNA microarray technique has allowed for more accurate diagnosis of CCOC through genetic profiling. Some studies have reported that frequent fission of the EWSR1 gene can provide a basis for diagnosis, as $83.3 \%$ of CCOCs manifest such genetic expresion, commonly with ATF $1^{11}$. However, clear cell carcinoma of minor salivary glands is also associated with such distinct characteristics, making it difficult to distinguish between CCOC and clear cell carcinoma of minor salivary glands ${ }^{5,11}$. Immunohistochemistry may be beneficial in this respect, as CCOC presents negative results for vimentin and muscle actin, while clear cell salivary gland tumors react positively with vimentin, muscle actin, cytokeratin, and S-100 protein ${ }^{12,13}$. Even in cases of biphasic-pattern CCOC, differentiating it from metastatic renal cell carcinoma may be difficult without incorporating the glycogen-negative tendency of $\mathrm{CCOC}^{8,14}$.A few other tumors, including ameloblastomas, ameloblastic carcinomas, calcifying epithelial odontogenic tumors, infected cysts, and squamous cell carcinomas, also involve differential diagnostic problems requiring accurate and reliable diagnostic criteria of $\mathrm{CCOC}^{15,16}$.

In this case, diagnosis of a malignant tumor was initially based on clinical and radiographic findings, but the lesion was later classified as ameloblastoma through incisional biopsy. The tissue displayed multiple clear cells, and an ameloblastic pattern was weakly observed. However, differential diagnosis of CCOC may be difficult due to its infrequency. Moreover, ameloblastic-pattern CCOC is uncommon, leading to misdiagnosis by unexperienced pathologists. Based on histopathologic findings, the authors considered the lesion an aggressive benign tumor, and the initial surgery was performed accordingly. However, during the operation, adhesion of the lesion to genioglossus muscle was observed, and bone destruction was more aggressive than expected. After histopathological reinvestigation, and considering the intraosseous origin of bone destruction, we determined the mass as CCOC. Ameloblastic carcinoma was one of our differential diagnoses, but CCOC was more plausible due to clear cell portions and less ameloblastic differentiation. Other considerations included clear cell carcinoma of the salivary gland and possible metastasis from renal cell carcinoma. The intraosseous origin of the lesion and immunohistochemical findings helped exclude a salivary gland tumor, and the histological appearance and vascularity pattern made the lesion distinguishable from metastasis of renal cell carcinoma.

Various treatment protocols for CCOC have been suggested in previous studies. Conservative approaches, such as curettage and enucleation, were followed until CCOC was reclassified as a malignancy, at which time many surgeons began performing wide surgical excision. Depending on lymph node involvement, neck dissection and surgical resection with a wide safety margin are now the gold standard for CCOC treatment ${ }^{17,18}$. A recurrence rate of $40 \%$ and a lymph node involvement rate of $10 \%$ have been reported ${ }^{5,7}$. Adjuvant therapy is not required in many cases, and lesion size and location, aggressiveness, and positive margin of resection must be considered beforehand ${ }^{9,17,18}$. In this case, the patient underwent both surgical resection with neck dissection and mandibular reconstruction with the fibular free flap. Because neither frozen biopsy of resection margins nor biopsy of the neck region showed a positive result, adjuvant therapy was not required.

A follow-up assessment for high-grade oral tumors was ordered due to the high recurrence rate of CCOC. In addition, long-term follow-up is mandatory for potential recurrence after as long as 20 years ${ }^{5}$. Patients should be well informed and understand the necessity for follow-up visits and management.

Because an unsuitable treatment protocol based on misdiagnosis from the initial assessment was followed, a second surgical interference for the intraosseous carcinoma was inevitable in this case. Prognosis was optimistic as the correct diagnosis was made within a short time and the proper surgical treatment was applied. However, if the first diagnosis had been accurate, the patient would not have undergone additional surgery, and his prognosis would have been more favorable. We conclude that, if malignant tendency of a lesion is recognized at first diagnosis, circumspective investigation of the specimen by an adept pathologist should be requested to establish an accurate diagnosis and choose the appropriate therapeutic approach.

\section{ORCID}

Jong-Cheol Park, https://orcid.org/0000-0001-5689-0258

Seong-Won Kim, https://orcid.org/0000-0002-9994-5121

Young-Jae Baek, https://orcid.org/0000-0003-3226-8266

Hyeong-Geun Lee, https://orcid.org/0000-0002-8378-8678

Mi-Heon Ryu, https://orcid.org/0000-0003-1283-9762

Dae-Seok Hwang, https://orcid.org/0000-0001-6899-1769

Uk-Kyu Kim, https://orcid.org/0000-0003-1251-7843 


\section{Authors' Contributions}

J.C.P. obtained data and wrote the manuscript. U.K.K. supplied the clinical data, controlled the drafting and reviewed the manuscript. M.H.R. interpreted pathologic slides. D.S.H. reviewed the manuscript and gave the informative comments. S.W.K., Y.J.B., and H.G.L. read and approved the manuscript.

\section{Acknowledgements}

This study was supported by the Basic Science Research Program through the Korean National Research Foundation funded by the Ministry of Education (No. NRF2012R1A1A2003550).

\section{Ethics Approval and Consent to Participate}

This case report was reviewed by the Institutional Review Board of Pusan National University Dental Hospital and was approved from deliberation (PNUDH-2017-022).

\section{Conflict of Interest}

No potential conflict of interest relevant to this article was reported.

\section{References}

1. Hansen LS, Eversole LR, Green TL, Powell NB. Clear cell odontogenic tumor--a new histologic variant with aggressive potential. Head Neck Surg 1985;8:115-23.

2. Barnes L. Pathology and genetics of head and neck tumours. Lyon: IARC Press; 2005.

3. Zhang J, Liu L, Pan J, Tian X, Tan J, Zhou J, et al. Clear cell odontogenic carcinoma: report of 6 cases and review of the literature.
Med Oncol 2011;28 Suppl 1:S626-33.

4. Chaine A, Pitak-Arnnop P, Dhanuthai K, Bertrand JC, Bertolus C. An asymptomatic radiolucent lesion of the maxilla. Clear cell odontogenic carcinoma. Oral Surg Oral Med Oral Pathol Oral Radiol Endod 2009;107:452-7.

5. Loyola AM, Cardoso SV, de Faria PR, Servato JP, Barbosa de Paulo LF, Eisenberg AL, et al. Clear cell odontogenic carcinoma: report of 7 new cases and systematic review of the current knowledge. Oral Surg Oral Med Oral Pathol Oral Radiol 2015;120:48396.

6. Eversole LR. Malignant epithelial odontogenic tumors. Semin Diagn Pathol 1999;16:317-24.

7. Avninder S, Rakheja D, Bhatnagar A. Clear cell odontogenic carcinoma: a diagnostic and therapeutic dilemma. World J Surg Oncol 2006;4:91.

8. Maiorano E, Altini M, Viale G, Piattelli A, Favia G. Clear cell odontogenic carcinoma. Report of two cases and review of the literature. Am J Clin Pathol 2001;116:107-14.

9. Surianti H, Chen PL, Hsue SS, Chang CM, Chang IPY, Chen YC. Clear cell odontogenic carcinoma of mandible--a case report. Taiwan J Oral Maxillofac Surg 2013;24:38-49.

10. Neville BW, Damm DD, Allen CP, Chi AC. Oral and maxillofacial pathology. 4th ed. St. Louis: Elsevier; 2016:663-4.

11. Hadj Saïd M, Ordioni U, Benat G, Gomez-Brouchet A, Chossegros $\mathrm{C}$, Catherine JH. Clear cell odontogenic carcinoma. A review. J Stomatol Oral Maxillofac Surg 2017;118:363-70.

12. Ogawa I, Nikai H, Takata T, Ijuhin N, Miyauchi M, Ito H, et al. Clear cell tumors of minor salivary gland origin. An immunohistochemical and ultrastructural analysis. Oral Surg Oral Med Oral Pathol 1991;72:200-7.

13. Mosqueda-Taylor A, Meneses-García A, Ruíz-Godoy Rivera LM, de Lourdes Suárez-Roa M. Clear cell odontogenic carcinoma of the mandible. J Oral Pathol Med 2002;31:439-41.

14. Eversole LR, Belton CM, Hansen LS. Clear cell odontogenic tumor: histochemical and ultrastructural features. J Oral Pathol 1985;14:603-14.

15. Adamo AK, Boguslaw B, Coomaraswarmy MA, Simos C. Clear cell odontogenic carcinoma of the mandible: case report. J Oral Maxillofac Surg 2002;60:121-6.

16. Kwon IJ, Kim SM, Amponsah EK, Myoung H, Lee JH, Lee SK. Mandibular clear cell odontogenic carcinoma. World J Surg Oncol 2015;13:284.

17. Kim M, Cho E, Kim JY, Kim HS, Nam W. Clear cell odontogenic carcinoma mimicking a cystic lesion: a case of misdiagnosis. J Korean Assoc Oral Maxillofac Surg 2014;40:199-203.

18. Ebert CS Jr, Dubin MG, Hart CF, Chalian AA, Shockley WW. Clear cell odontogenic carcinoma: a comprehensive analysis of treatment strategies. Head Neck 2005;27:536-42. 